\title{
Using Remote Laboratory eLab3D for a Broader Practical Skills Training in Electronics
}

\author{
A. Carpeño, S. López and J. Arriaga
}

\begin{abstract}
This paper briefly presents some relevant aspects of an innovative educational resource that allows real experimentation through Internet in the area of electronics. The developed platform, named eLab3D, is based in a 3D environment in which the user can conduct all the operations that he/she would carried out in a hands-on laboratory. The authors intend to demonstrate the basic operation of the platform to perform electronics experiments.
\end{abstract}

Index Terms - remote laboratory, electronic experiments, electronic engineering education, 3D virtual worlds, eLearning.

\section{INTRODUCTION}

Online engineering education is increasingly important for a growing number of higher education institutions. The acquisition of practical skills and the application of theoretical concepts and principles to perform real experiment are very important in engineering learning. Therefore, the use of remote laboratories as an educational resource in engineering education is undergoing a huge expansion in recent years [1]. Following this trend the Technical University of Madrid is developing virtual and remote laboratories in several topics seeking to improve the efficiency and effectiveness of its educational processes. eLab3D is one of these laboratories. It is a remote laboratory in which the students can conduct online real experiments in the area of electronics through an interface based on a 3D virtual world.

eLab3D design is founded not only on the possibilities that innovative 3D technologies can offer but also on important educational aspects, such as:

- The creation of a more flexible, motivating and selfpaced learning environment.

- Students' acquisition of the majority of the practical competencies achievable in a hands-on electronics laboratory [2].

- Making the equipment of the university available to society and especially to groups with limited resources or accessibility problems.

- Promoting the use of methodologies that encourage students' active and cooperative learning.

The demonstration will show some of the educational opportunities that eLab3D can offer.

\section{ELAB3D DESCRIPTION}

The key aspects of the developed virtual world (Virtual Lab) as well as the most relevant characteristics of eLab3D are presented in the following sections.

\section{A. Virtual Lab}

The user interface through which it is possible to access the remote laboratory is an Opensim-based virtual world named Virtual Lab. To access the virtual world the student must install a free 3D viewer application on the computer. The interaction with the objects in the virtual world and with other users is accomplished by means of an avatar.

Virtual Lab resembles a building containing several rooms in which teachers and students can perform different learning activities, such as meeting rooms for collaborative learning, video room for presentations or discussion forums, and laboratory rooms for experimental activities.

In the laboratory rooms, as shown in Fig. 1, there are several workbenches where students conduct their laboratory practice and can interact both with other students and with the teacher. As shown in Fig. 2, each workbench has the same resources usually found in a hands-on laboratory, i.e. instruments, circuit boards, cables and components. The experimentation boards now available allow the design and test of circuits based on operational amplifiers, diodes, transistors and passive components. Fig. 3 shows the experimentation board used by the students to practice on different circuit configurations based on operational amplifier.

You can find a video that shows the functioning details of eLab3D in the following link:

https://www.youtube.com/watch? $=\mathrm{rZ5JTzch} 2 \mathrm{cY} \& \mathrm{n}$ oredirect $=1$

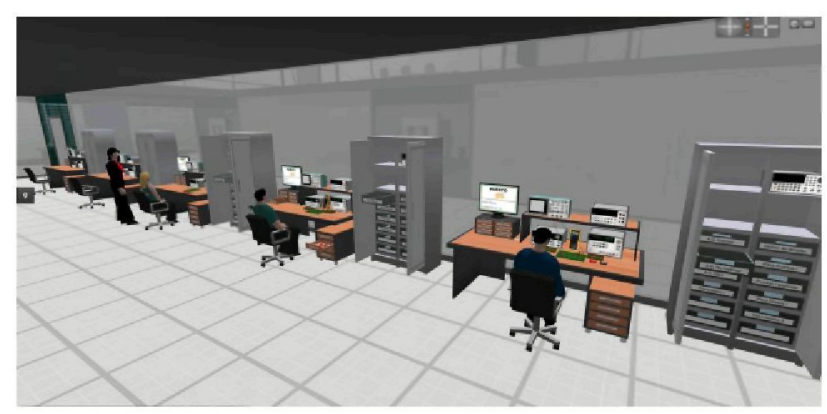

Figure 1. Laboratory room 


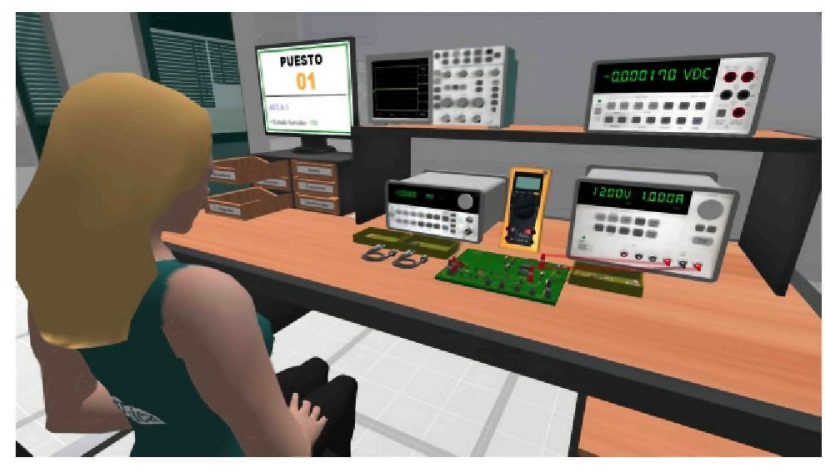

Figure 2. Workbench

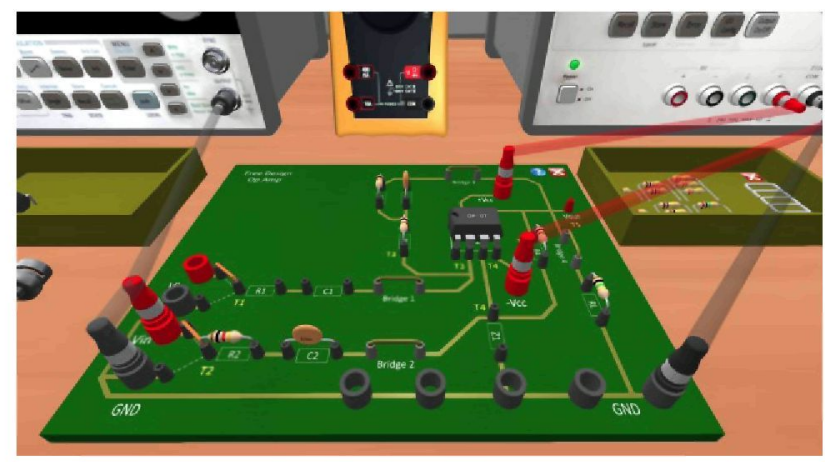

Figure 3. Operational Amplifier Experimentation board

\section{B. Features}

The most important eLab3D characteristics are derived from the educational principles we wanted to meet and the recommendations presented by experts on remote laboratories in the field of electronics [3] [4] [5].

From the technical point of view, the following characteristics can be highlighted:

a) Scalability. Both the system hardware and the developed software applications are modular. Some parts are even reusable. Therefore, it is not very dificult to extend system capacities with new modules.

b) Availability $24 / 7$.

c) Multi-platform. The system is accessible through a standard $3 \mathrm{D}$ viewer, available on multiple platforms (Linux, Windows or Mac).

d) Flexibility. It is also very flexible, allowing the adaptation to users with diferent paces, needs or limitations.

e) Versatility. Multiple functionalities are available. The user can implement the circuits by choosing and inserting the components, can change instruments settings, can select the measuring points and connect the corresponding cables between them and the instruments inputs and outputs.

f) Multi-user. Multiple users can operate simultaneously, performing different types of experiments.

g) Sense of realism. Virtual Lab was designed to cause an immersive and motivating learning experience, because these characteristics are usually correlated with higher students' success. eLab3D has a novel functionality, not provided by most developed remote laboratories currently, that also increases the feeling of realism. Each object in the workbench reflect in real time the actual state of the circuit and instruments, i.e. the system is updated automatically according to the user's actions with cables, components and instruments even though the assembly of the circuit had not been concluded.

From the pedagogical perspective, the system also has two features that are intended to promote active learning:

a) Learning by doing. The user's activities are always centered on decision making tasks, such as choosing the appropriate experimentation board, assembling the circuit components according to the configuration under test, selecting and configuring the instruments and making measurements.

b) Collaborative environment. The platform offers useful communication tools necessary to create social spaces that foster collaborative learning and allow teachers the supervision and guidance of students' learning.

\section{CONCLUSIONS}

eLab3D is a resource that facilitate students' acquisition of practical skills in the field of electronics, focusing on the key competences related to each phase of the development cycle of an electronic circuit: analysis, design, prototyping, and testing using real instrumentation. It is a useful and versatile platform that can be used in different educational levels, even in lifelong learning or in the industrial field. It is particularly suitable for improving the efficiency of online education programs, facilitating the student's learning anywhere and anytime. It contributes to fostering life-long learning initiatives and improving education in economically disadvantaged areas that would otherwise have difficult access to such resources. Examples of use of elab3D are proposed to be demonstrated during the Exhibition Session at REV 2014.

\section{REFERENCES}

[1] L. Gomes and S. Bogosyan, "Current trends in remote laboratories", IEEE Transactions on Industrial Electronics, vol. 56 , no. 12 , pp. 4744-4756, 2009

[2] L. Feisel and A. Rosa, "The role of the laboratory in undergraduate engineering education", Journal of Engineering Education, vol. 94, no. 1, pp. 121-130, 2005

[3] I. Gustavsson, "On remote electronics experiments", in Using Remote Labs in Education, J. García Zubía and G. R. Alves (eds.), University of Deusto, Bilbao, 2011, pp. 157-176

[4] A. Bagnasco, A. Boccardo, P. Buschiazzo, A. Poggi, and A. M. Scapolla, "A service-oriented educational laboratory for electronics," IEEE Trans. Ind. Electron., vol. 56, no. 12, pp. $4768-$ 4774, Dec. 2009.

[5] Z. Nedic and J. Machotka, "Remote laboratory NetLab for effective teaching of 1st year engineering students", International Journal of Online Engineering, vol. 3, no. 3, 2007. 